\title{
INTERACCIÓN CIUDADANA FRENTE AL MENSAJE DE UN ACTOR POLITICO EMERGENTE EN FACEBOOK
}

Ysabel Briceño Romero, María Fernanda Acevedo Solano, Daniela Cogollo Rodríguez Lina Sanabria Muñoz 


\title{
CITIZEN INTERACTION AND THE MESSAGE OF AN EMERGING POLITICAL ACTOR ON FACEBOOK
}

\author{
AUTORAS \\ Ysabel Briceño Romero \\ Doctora en Ciencias Humanas. Docente e investigadora Programa \\ Comunicación Social.Universidad Autónoma de Bucaramanga. \\ Correo electrónico: ybriceno@unab.edu.co \\ Estudiantes Comunicación Social. Semillero de investigación \\ Comunicación Cultura y Medios - CUME \\ Universidad Autónoma de Bucaramanga \\ María Fernanda Acevedo Solano \\ Correo electrónico: macevedo473@unab.edu.co \\ Daniela Cogollo Rosdríguez \\ Correo electrónico: dcogollo832@unab.edu.co \\ Lina Sanabria Muñoz \\ Correo electrónico: Isanabria450@unab.edu.co
}

\begin{abstract}
RESUMEN
En este artículo se despliegan los resultados de una revisión de las reacciones de usuarios en la red social Facebook ante mensajes emitidos por un actor político emergente, centrándonos en la interacción como la expresión de nuestro objeto de estudio. La propuesta buscó caracterizar tres niveles de respuesta a publicaciones sobre temas públicos relacionados con la gestión de una ciudad de Colombia (Bucaramanga), frente a 234 publicaciones emitidas en esta red social por Rodolfo Hernández, un actor político emergente que logra ser electo alcalde. Los resultados apuntan a una tendencia progresiva en las reacciones a las publicaciones en Facebook del emisor político estudiado. En general, se refleja una atención diferenciada por años hacia núcleos temáticos que caracterizan el discurso de actores políticos emergentes.

Palabras claves: outsider político, e-ciudadanía, comunicación política 2.0, interacciones digitales, Facebook.
\end{abstract}




\section{INTRODUCCION}

Dos años antes de ser elegido como el nuevo alcalde de Bucaramanga (Colombia), Rodolfo Hernández abrió su propio espacio en Facebook como actor político emergente, forjando desde entonces sus lazos con la comunidad local por medio de esta red social para dar a conocer sus ideas y promover un nuevo movimiento sin hacer uso de las herramientas políticas tradicionales.

Con 77 mil 238 votos, el 25 de octubre de 2015 en la capital del Departamento de Santander de Colombia, el hasta entonces conocido como el ingeniero Rodolfo Hernández Suárez, se convirtió en el nuevo alcalde del municipio Bucaramanga contra todo pronóstico; de un total de 281 mil 800 sufragantes, el $28,83 \%$ apoyó al nuevo candidato sin un partido político tradicional.

De acuerdo con lo que plantea Rivas Leone (2002), las características de Rodolfo Hernández (en adelante: $\mathrm{RH}$ ) como candidato pueden entrar en la clasificación de un outsider político: una figura que se presenta como una alternativa con cierta aceptación y viabilidad, que, además, hace uso de un discurso con fuerte contenido emotivo y mesiánico, a la vez que critica y cuestiona la institucionalidad tradicional.

RH se postula a la Alcaldía de Bucaramanga con un movimiento político independiente conocido como Lógica, Ética y Estética, con el que reunió 130 mil firmas. Con su discurso enfocado en la anticorrupción y la premisa de "no robar", consiguió que la mayoría de ciudadanos depositara su confianza en él, atendiendo a lo que algunos teóricos reportan como "respuesta a una suerte de fatiga cívica, que se ha ido extendiendo, producto del desencanto provocado por la promesa incumplida de la democracia" de los gobiernos tradicionales anteriores (Rivas Leone, 2002, p. 7).
Aunque RH demostró adaptar sus propuestas electorales dentro del marco establecido (partidos políticos), centró su discurso de malestar permanente señalando a los actores políticos tradicionales.

Pese a que durante el auge de las elecciones este candidato no tuvo una campaña política tradicional, hizo uso de la red social Facebook como una plataforma política para acercarse a los ciudadanos e interactuar con ellos desde 2013, dos años antes de ser electo alcalde.

Facebook ha llegado a ser considerado como una plataforma efectiva de comunicación política. Autores como Martínez (2012) han seleccionado esta red como estudio de comunicación política porque permite dar a conocer planes e ideas, establecer vínculos más próximos con los ciudadanos, debatir en foros, recoger el interés de la gente y hacer campañas más participativas y abiertas.

Este panorama nos motivó a preguntarnos por las reacciones de los ciudadanos bumangueses en Facebook ante el discurso de Rodolfo Hernández como outsider político. En esta revisión se hizo un conteo manual de las respuestas registradas en Facebook, bajo la modalidad de interacción que permite esta plataforma (clic a "me gusta", cantidad de publicaciones compartidas y número de comentarios realizados), durante los últimos cuatro meses de los años 2013, 2014, 2015, en medio de un contexto de elecciones regionales en Colombia, al final del período analizado. 


\section{MARCO TEÓRICO}

\section{1.- Los outsiders como actores políticos emergentes}

La democracia, como proyecto en permanente construcción, sigue siendo aún muy inestable en América Latina, dada su corta trayectoria. Uno de los retos que se plantea la región es la resolución de los conflictos sociales, respetando la institucionalidad democrática. Ante el aumento de la pobreza y la desigualdad social en la última década del siglo XX en América Latina, además de aspectos nocivos como la corrupción, los ciudadanos tienden a oxigenar la elección en actores políticos novedosos. En este sentido, el Informe del PNUD (2004) reporta que los ciudadanos "empiezan a distinguir entre la democracia como sistema de gobierno y el desempeño de los gobernantes en particular. Muchos de estos ciudadanos

son simplemente 'demócratas insatisfechos', un fenómeno bien conocido en muchas democracias establecidas que explica parcialmente por qué los movimientos de oposición no tienden hoy hacia soluciones militares sino hacia líderes populistas que se presentan como ajenos al poder tradicional y que prometen perspectivas innovadoras" (p.14).

Estas nuevas figuras de liderazgo que emergen de un desencanto general frente a la política, y del empobrecimiento generalizado tras la crisis de la década perdida (Burbano, 1998) son reconocidos como outsiders políticos, caracterizados por ganar relevancia, no a través de un partido establecido, sino como independientes o en asociación con un nuevo partido (no tradicional) (Barrios, 1996); estas figuras han sido caracterizadas como innovadoras, populares, mesiánicas y revolucionarias (Rivas Leone y Calderón, 2004) en el juego político latinoamericano de las últimas décadas.
Insertos en las nuevas formas de comunicación política, permitidas por el uso de Internet, los outsiders políticos también han hecho uso de las Tecnologías de Información y Comunicación para transmitir sus ideas y ganarse la confianza de los ciudadanos, en medio de un ambiente de redes sociales que deja registro de una interacción emergente. Una de las expresiones que puede quedar registrada en las redes sociales digitales es el apoyo político y desafección política, trabajada por autores como Almond y Verba (2007), Abad y Trak (2013), Norris (1999) y Murga (2008) en América Latina, como una respuesta de rechazo a la política tradicional que abona terreno para el apoyo a los outsiders políticos, un camino nuevo que plantea retos en términos de la investigación académica.

\section{2.- Facebook como plataforma de interacción social}

Las redes sociales digitales pudieran comenzar a erigirse como expresión de un sentimiento ciudadano ya trabajado por algunos autores. Cabañes (2010) ha asomado el término 'e-ciudadanía' o 'ciudadanía digital', para referirse a individuos que se reconocen y son reconocidos como parte de una nueva comunidad para poder asumir derechos y deberes.

Algunos autores le confieren a las redes sociales una condición que empodera al ciudadano, desde las aspiraciones clásicas, generar protestas, convocar a la acción y defender intereses colectivos (Gutiérrez-Rubí, 2015). Esta nueva comunidad, expresada en las redes sociales, podría impulsar la participación social que, desde el punto de vista de autores como Sánchez (2009), fomenta la intervención del ciudadano en los intereses públicos, en un espacio en el que encuentra objetivos comunes. 
La posibilidad que tienen los ciudadanos para interactuar con candidatos políticos por medio de las redes sociales, sugiere una noción emergente en términos de participación política, con ciudadanos que no son considerados sólo como opinión pública, sino como protagonistas de la vida política fuera de los períodos electorales (Martínez, 2012).

La relación de los usuarios de Internet con los mensajes a los que se enfrentan en diversas redes sociales y su capacidad para producir contenidos ya ha empezado a problematizarse, siendo una característica recurrente en la reflexión, la necesidad de abordar la interacción desde diversos niveles.

Autores como Kiss (2006), asoman la idea de interacciones digitales, refiriéndose a las nuevas transformaciones estructurales que conllevan a pensar los elementos del proceso de comunicación de una manera distinta, dado que la web multiplica sus funciones mediáticas, una perspectiva particularmente útil para nuestra investigación:

...ahora hablamos de procesos interactivos más que de procesos comunicativos, en nuestra referencia a la relación que establecemos con Internet. Estamos frente a un cambio radical en las operaciones cognitivas y motoras que realiza el decodificador al relacionarse en forma individual y creativa con un canal de comunicación, mismo que exige un compromiso mucho más explícito y directo de su parte, más allá de las operaciones sociales que implica la recepción activa de los mensajes presentados por los medios de comunicación colectiva tradicionales (p. 48).
Entendida la interacción como intercambio y la negociación del sentido entre dos o más participantes situados en contextos sociales (O'Sullivan, citado en Rizo, 2006), podemos acercarnos a comprender nuevas relaciones entre quienes ofrecen ideas políticas en las redes sociales y quienes destacan sus reacciones a partir de los códigos permitidos por estas plataformas. Siguiendo a Rizo (2006) podríamos partir de la interacción en las redes sociales como una construcción de sentidos compartidos sobre la realidad social.

Facebook surge en 2004 como un directorio web en línea para el uso de todos los integrantes de las fraternidades de la Universidad de Harvard, lugar donde estudió su creador Mark Zuckerberg, y en septiembre de 2006 abre sus puertas a todos los usuarios de internet que tuvieran un correo para acceder a esta página, convirtiéndose en el portal más representativo y usado a nivel mundial donde se pueden tejer redes sociales.

Facebook despliega opciones a las que se les adjudica el éxito del uso de esta plataforma. Entre las funciones básicas se encuentra la posibilidad de compartir en red contenidos, vincular a otros sitios de la web (links) y comentar sobre lo que aparece en el perfil de otros usuarios que forman parte de una red, cuyos miembros interactúan voluntariamente.

Estas funciones promueven un registro de la circulación del contenido en Facebook, así como del perfil del usuario ante temas específicos, dado que la plataforma deja un registro de sus interacciones. Las características principales son:

2. "MAV, Entrevista con Marisa González". Recuperado el 13/09/2017 de: https://vimeo.com/39377538 
Función de like o me gusta: aplicación que permite a los usuarios indicar que alguna publicación, actualización de estado, video, foto o página, es de su agrado dando un clic al botón que indica la palabra "me gusta" y enviando una notificación al perfil de la persona que lo subió a la plataforma (Ochoa y Uribe, 2015). Esta función, conocida como "like" o "me gusta" está representada por medio de una mano de color azul con blanco que tiene el dedo pulgar hacia arriba, como una forma de aprobación al contenido con el que se interactúa.

Función para comentar: permite que los usuarios puedan responder a las publicaciones de terceros, con el fin de expresar sus puntos de vista frente al contenido, dejando registro de interacción directa con el emisor, pero a su vez, creando ambientes de discusión entre quienes comentan.

Función de compartir: permite al usuario distribuir el mensaje de terceros, potenciando la visibilidad del contenido a otros usuarios, pero con la función adicional de poder incluir contenidos personalizados que ampliarán el registro discursivo sobre el tema publicado y dejando un registro autónomo de la relación con la publicación.

Para Gómez y otros (2013), la interfaz de Facebook sugiere e invita a hacer, generándose relación entre los usuarios y un "objeto técnico" que no sólo lleva consigo funcionalidades y utilidades, sino que también está fuertemente cargado de valores y símbolos, postura que suscribimos como un acercamiento a nuevas rutas de comprensión en aquellas formas de expresión ciudadana reflejadas en reacciones y disposición colectiva a participar en la cadena distribuida de mensajes alusivos a intereses públicos.
El registro de la interacción del usuario en plataformas como Facebook, podría expresar tendencias en la opinión pública frente a temas relacionados con asuntos públicos, bajo la modalidad de política 2.0, definida como una nueva forma de hacer y pensar la política (Martínez, 2013).

A partir del uso de sus funciones básicas, autores como Pérez (2009) consideran a Facebook una plataforma que potencia la expresión de apoyo a actores políticos: más allá de seguidores, son un público objetivo, se trata de potenciales votantes. Esta tendencia propone a Facebook como un espacio que deben asumir los políticos con responsabilidad, dado que muchos votantes potenciales causales valoran positiva (o negativamente) tal experiencia (Pérez, 2009).

\section{3.- Antecedentes}

Desde 2008 las redes sociales comenzaron a tenerse en cuenta como una herramienta de éxito, luego de que en las elecciones norteamericanas el para entonces candidato Barack Obama lograra ganar la presidencia de este país enfocando su estrategia en nuevas herramientas de comunicación política. El despliegue y estrategia del equipo de Obama en internet se focalizó en sitios como BarackObama.com, su perfil de Facebook, Twitter y MySpace, MyBarackObama. com, You Tube, Barack TV y el sitio WAP Obama Mobile (González, 2010).

En América Latina encontramos varios ejemplos representativos que ilustran cómo ha sido el éxito de outsiders políticos por medio de su interacción con los ciudadanos por medio de redes sociales como Facebook, como plataforma de comunicación política. En Colombia, el caso más relevante fue la campaña electoral del año 2010, con la candidatura a la 
presidencia de Antanas Mockus, representante del movimiento emergente Partido Verde, cuyo uso e interacción creciente en las redes sociales lo convierten En referencia importante en esta tendencia (Fernández, 2012).

También se pueden destacar otras revisiones que han desplegado búsquedas similares acerca de la incorporación de las redes sociales en las campañas electorales. Hernández (2013) aborda en una tesis de postgrado acerca el uso estratégico de Facebook y Twitter por parte de candidatos a las alcaldías en las elecciones de el Salvador. Ferré (2014) enfoca su estudio en la participación de los jóvenes frente al uso de las redes sociales, un estudio comparativo en elecciones de España y Brasil. En otros trabajos, por su parte, se han asomado ideas respecto al caso específico de Facebook, como una plataforma que brinda posibilidades comunicativas "en cuanto a su capacidad de inmediatez, intuitividad e interactividad, para humanizar la conversación con lenguajes atractivos, eficaces, cercanos y correctos" (Berlanga y Martínez, 2010).

\section{METODOLOGIA:}

Se trata de un estudio cuantitativo en su primera fase, a partir de la cual se representan las tendencias de interacción, según las reacciones (número de like, comentarios y publicaciones compartidas). En una segunda fase, se realiza una caracterización cualitativa de aquellas publicaciones destacadas por el mayor número de reacciones en los distintos niveles, lo cual permitió identificar núcleos discursivos sobre los cuales los usuarios de Facebook centraron su atención; esta fase fue definida por la detección de construcciones textuales, tipos de imágenes utilizadas, uso de frases recurrentes y estrategias argumentativas.
Descarga de datos: se realizó una descarga manual de 232 publicaciones realizadas en el Facebook de $\mathrm{RH}$ en el siguiente período: septiembre-diciembre 2013, 2014 y 2015. Se tomaron como referencia los últimos cuatro meses del año, con el fin de realizar una comparación entre el período cercano previo, durante y posterior a las elecciones regionales de Colombia (25 de octubre del año 2015) y una revisión en los años anteriores.

Las publicaciones fueron identificadas, según la reacción de los usuarios de Facebook, desde los ítems siguientes: clic a "me gusta", número de publicaciones compartidas y número de comentarios realizados.

Calificación de la interacción: planteamos una revisión en los siguientes niveles, según el grado de esfuerzo que implican las reacciones ante el discurso de un actor político:

Nivel 1 de interacción: reacciones por medio de "me gusta". Implica una interacción básica que el usuario plantea, al reaccionar haciendo click en el botón "me gusta" y que podría significar una forma mínima de relación con el emisor.

Nivel 2 de interacción: comentarios al contenido. Establece una relación más directa del usuario con el emisor político, convirtiéndose en sujeto activo para la publicación del contenido, en un escenario que puede provocar una red de reacciones en cadena con otros usuarios que intervienen en este nivel.

Nivel 3 de interacción: compartir el contenido. Implica una relación más autónoma del usuario frente al contenido que el emisor ha planteado, en tanto que propone una ruta adicional de multiplicación del mensaje, pudiendo además agregar información propia, contribuyendo a nueva información y reforzando la característica distribuida de la publicación de mensajes en redes sociales. 


\section{RESULTADOS:}

Durante los períodos 2013, 2014 y 2015, las publicaciones de RH tuvieron las siguientes reacciones, caracterizadas por nivel: 2.129, 6.804 y 235.977 clic a "me gusta", respectivamente; 146, 892 y 17.030 comentarios realizados, correspondientemente; y 95, 1.017 y 70.470 publicaciones compartidas, respectivamente, como se registra en el Gráfico y Tabla1.
En un total de 284 publicaciones realizadas en Facebook, RH logra una interacción progresiva de los bumangueses, en todos los niveles, alcanzando un total de 334.560 reacciones; la tendencia se dispara hacia el hacia el último año analizado, en medio de un escenario electoral.

\section{Resultados interacciones}

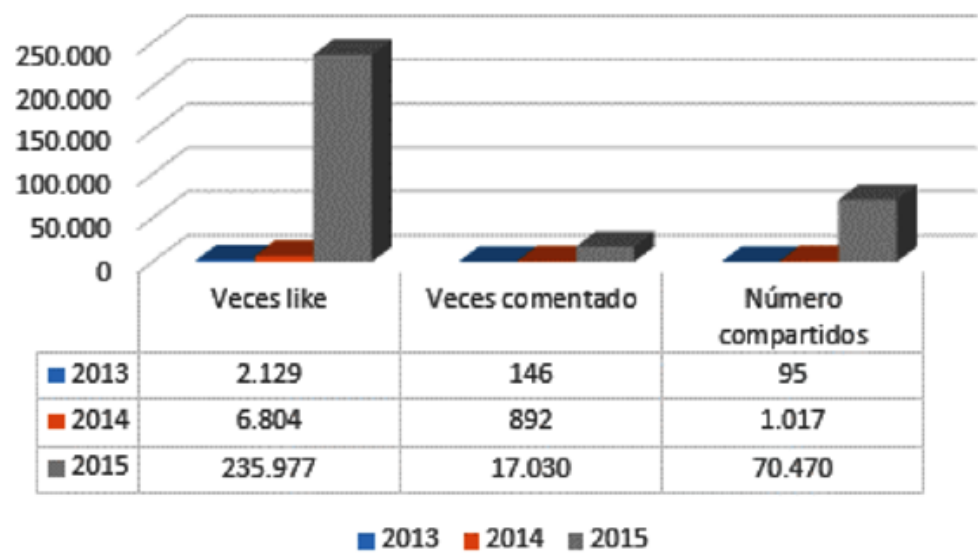

Gráfico 1: Número de interacciones durante el período estudiado

\section{Caracterización por niveles:}

Con una tendencia progresiva, de mayor énfasis en el último año, el nivel de mayor interacción en todo el período estudiado es el más básico o nivel 1 (clic a "me gusta") y se destaca un alza diferenciadora en la interacción de los usuarios en el nivel 3 (tendencia a reproducir y comentar el mensaje).

\begin{tabular}{|l|l|l|l|l|l|}
\hline Año & $\begin{array}{l}\text { Publicaciones } \\
\text { RH }\end{array}$ & $\begin{array}{l}\text { Nivel 1 } \\
\text { ("like" o } \\
\text { "me gusta") }\end{array}$ & $\begin{array}{l}\text { Nivel 2 } \\
\text { (comentarios) }\end{array}$ & $\begin{array}{l}\text { Nivel 3 } \\
\text { (compartidos) }\end{array}$ & Total \\
\hline $\mathbf{2 0 1 3}$ & 82 & 2.129 & 146 & 95 & 2.370 \\
\hline $\mathbf{2 0 1 4}$ & 51 & 6.804 & 892 & 1.017 & 8.713 \\
\hline $\mathbf{2 0 1 5}$ & 151 & 235.977 & 17.030 & 70.470 & 323.477 \\
\hline Total & 284 & 244.910 & 18.068 & 71.582 & 334.560 \\
\hline
\end{tabular}

Tabla 1: Caracterización por niveles de interacción 


\begin{tabular}{|c|c|c|c|}
\hline Año & Características de la publicación & $\begin{array}{c}\text { Tipo de } \\
\text { interacción }\end{array}$ & Énfasis discursivo \\
\hline & $\begin{array}{l}\text { Texto: } \\
\text { "Estudiar y comprender a Bucaramanga en su } \\
\text { totalidad nos dará herramientas para gestionar un } \\
\text { desarrollo igualitario basado en la convivencia". } \\
\text { En esta publicación aparece una imagen de RH } \\
\text { sentado en su escritorio mirando un mapa de la } \\
\text { ciudad, con un lápiz en la mano. La pose expresa } \\
\text { planificación. } \\
\text { Debajo del texto que acompaña la imagen, } \\
\text { aparece el nombre de su movimiento político } \\
\text { emergente "Lógica, Ética y Estética". }\end{array}$ & $\begin{array}{l}\text { Interacción } \\
\text { nivel 1: } 82 \\
\text { "me gusta" }\end{array}$ & $\begin{array}{l}\begin{array}{l}\text { Herramientas de gestión, } \\
\text { convivencia y planificación } \\
\text { de la ciudad. }\end{array} \\
\text { Énfasis en el eslogan del } \\
\text { movimiento emergente: } \\
\text { "Lógica, Ética y Estética". } \\
\text { La imagen se centra en RH. }\end{array}$ \\
\hline 2013 & $\begin{array}{l}\text { Texto: } \\
\text { "Con una inversión cercana a los } 110 \text { millones de } \\
\text { pesos, estamos beneficiando cerca de } 5 \text { mil } \\
\text { estudiantes de La Escuela Normal Superior de } \\
\text { Piedecuesta. } \\
\text { Donado por Lógica, Ética \& Estética". } \\
\text { En esta publicación RH demuestra su } \\
\text { preocupación por la Inversión en educación en la } \\
\text { ciudad. Para ello utiliza el recurso de "ubicación", } \\
\text { con el que da a entender que está presente en el } \\
\text { lugar donde hizo la donación de computadores, } \\
\text { que es la sala de informática Cecilia Suárez de } \\
\text { Hernández de La Escuela Normal Superior de } \\
\text { Piedecuesta. } \\
\text { El texto está acompañado de un álbum de } 20 \text { fotos } \\
\text { en las que en su mayoría aparecen algunos niños } \\
\text { de una institución educativa de la ciudad, en la } \\
\text { que se evidencia una donación de equipos de } \\
\text { computación. El álbum tiene activada la función } \\
\text { de "ubicación". } \\
\text { El álbum incluye imágenes de reconocimiento }\end{array}$ & $\begin{array}{l}\text { Interacción } \\
\text { nivel 2: } 19 \\
\text { comentarios }\end{array}$ & $\begin{array}{l}\text { Inversión privada. } \\
\text { El texto destaca la institución } \\
\text { educativa beneficiada por la } \\
\text { donación. } \\
\text { Se enfatiza el nombre del } \\
\text { movimiento emergente } \\
\text { "Lógica, Ética y Estética". } \\
\text { Las imágenes destacan la } \\
\text { población infantil y las TIC } \\
\text { como factor de incidencia. } \\
\text { Algunas se centran en RH y } \\
\text { su aporte. }\end{array}$ \\
\hline
\end{tabular}




\begin{tabular}{|c|c|c|c|}
\hline & $\begin{array}{l}\text { institucional a RH; en una de ellas se enfatiza el } \\
\text { texto de un diploma, en el que se agradece a RH } \\
\text { por el "aporte realizado en favor de toda la } \\
\text { Comunidad Educativa Normalista". }\end{array}$ & & \\
\hline & $\begin{array}{l}\text { Texto: } \\
\text { "Transformaciones que mejoran la Calidad de } \\
\text { Vida. } \\
\text { Cancha Sintética la Esperanza III, Desarrollada } \\
\text { por Lógica, Ética y Estética. } \\
\text { Ing Rodolfo Hernández Suarez". } \\
\text { El texto está acompañado de un fotomontaje con } \\
\text { dos imágenes, comparando un "antes" y un } \\
\text { "después" de la transformación de un } \\
\text { espacio intervenido por una cancha de fútbol, } \\
\text { sintética. } \\
\text { En la parte superior de la imagen aparece el logo } \\
\text { del movimiento político y la frase: "Con Lógica, } \\
\text { Ética y Éstética estamos ayudando a transformar } \\
\text { la vida de la gente". En la parte inferior derecha } \\
\text { de la fotografia está ubicado el nombre de la } \\
\text { página web del movimiento. }\end{array}$ & $\begin{array}{l}\text { Interacción } \\
\text { nivel 3: } 14 \\
\text { compartidos }\end{array}$ & $\begin{array}{l}\text { Transformación. Calidad de } \\
\text { vida. } \\
\text { El texto destaca el sector } \\
\text { beneficiado por la donación } \\
\text { del movimiento emergente } \\
\text { "Lógica, Ética y Estética" y } \\
\text { es firmado explícitamente } \\
\text { como: Ing. Rodolfo } \\
\text { Hernández. } \\
\text { La estrategia de imagen con } \\
\text { un antes y un después se } \\
\text { centra en transformación } \\
\text { pública favorable, a partir de } \\
\text { una acción generada por RH. } \\
\text { Las imágenes enfatizan el } \\
\text { deporte como eje. }\end{array}$ \\
\hline \multirow[t]{2}{*}{2014} & $\begin{array}{l}\text { Texto: } \\
\text { "IDEA MARAVILLOSA LLEVADA A LA } \\
\text { RUINA. PARTE III } \\
\text { Los buses de Metrolínea son insuficientes para la } \\
\text { demanda. } \\
\text { Metrolínea fue diseñado por las mismas manos } \\
\text { que siempre están metidas en las contrataciones. } \\
\text { Manos que piensan en los contratos y no en la } \\
\text { ciudad". } \\
\text { El texto está acompañado del link a la página del } \\
\text { Movimiento Lógica, Ética y Estética, en donde se } \\
\text { encuentra una serie de textos dedicados al tema } \\
\text { (parte I y parte II). }\end{array}$ & $\begin{array}{l}\text { Interacción } \\
\text { nivel } 1 \text { y } 3: \\
717 \text { "me } \\
\text { gusta" } \\
238 \\
\text { compartidos }\end{array}$ & $\begin{array}{l}\text { Mala gestión pública } \\
\text { tradicional. } \\
\text { Vicios de la gestión pública } \\
\text { en las contrataciones. } \\
\text { El tema enfatiza la mala } \\
\text { gestión en el transporte } \\
\text { público, con el Metrolínea } \\
\text { como caso ilustrador de la } \\
\text { ciudad. }\end{array}$ \\
\hline & $\begin{array}{l}\text { Texto: } \\
\text { "Una opción diferente para los habitantes de } \\
\text { Bucaramanga. } \\
\text { "El corazón de mi campaña es no robar el dinero } \\
\text { público". } \\
\text { El texto resalta el titular de un diario local, con las } \\
\text { declaraciones de RH, acompañado del url de la } \\
\text { noticia. }\end{array}$ & $\begin{array}{l}\text { Interacción } \\
\text { nivel } 2: 167 \\
\text { comentarios }\end{array}$ & $\begin{array}{l}\text { La anticorrupción romo } \\
\text { centro de la campaña } \\
\text { electoral. }\end{array}$ \\
\hline
\end{tabular}




\begin{tabular}{|c|c|c|c|}
\hline 2015 & $\begin{array}{l}\text { Texto: } \\
\text { "¡Hoy somos más!, Se ha expresado el voto } \\
\text { independiente, le hemos dicho NO a la } \\
\text { corrupción. Todos sabemos que de estos 76mil } \\
\text { votos NO HAY NI UN SOLO VOTO comprado, } \\
\text { ¡Son votos libres! \#SinTamalySinLechona. A } \\
\text { nuestros voluntarios, seguidores y todos los que } \\
\text { han confiado su voto en mí, ¡MUCHAS } \\
\text { GRACIAS! Hoy comienza el verdadero cambio } \\
\text { en \#Bucaramanga \#JuntosPodemosHacerlo". } \\
\text { En el texto escrito se incluyen tres hashtags } \\
\text { (etiquetas) usadas durante la campaña: } \\
\text { \#SinTamalySinLechona, \#Bucaramanga } \\
\text { \#JuntosPodemosHacerlo. } \\
\text { La imagen que acompaña el texto es un } \\
\text { fotomontaje de RH con un rostro alegre y un } \\
\text { fondo verde que representa el color de su } \\
\text { movimiento político emergente "Lógica, Ética y } \\
\text { Estética", cuyo logo aparece en la parte inferior } \\
\text { de la imagen. En la mitad del fotomontaje aparece } \\
\text { la palabra 'Gracias' en tamaño grande y el } \\
\text { hashtag \#IngRodolfoHernandez. }\end{array}$ & $\begin{array}{l}\text { Interacción } \\
\text { en todos los } \\
\text { niveles: } \\
15.409 \text { "me } \\
\text { gusta } \\
2.190 \\
\text { comentarios } \\
" \quad 4.108 \\
\text { compartidos }\end{array}$ & $\begin{array}{l}\text { Esperanza, promesa de } \\
\text { verdadero cambio, } \\
\text { agradecimiento, tono plural } \\
\text { de ganancia colectiva. } \\
\text { Se enfatiza la idea } \\
\text { diferenciadora: "no hay un } \\
\text { solo voto comprado". }\end{array}$ \\
\hline
\end{tabular}

Tabla 2: caracterización de las publicaciones con mayor interacción en el período estudiado

Año 2013: la visibilidad de un movimiento emergente

Los bumangueses despliegan su interacción en Facebook hacia un actor político emergente que promueve inicialmente una posible transformación en la calidad de vida. Los mensajes que logran captar mayor atención y sobre los cuales el usuario reacciona con más actividad en este año, están centrados en: un actor novedoso relacionado con la gestión ciudad, con pose de planificador, amparado en un movimiento emergente que tiene etiqueta: "Lógica, Ética y Estética", pero en cuya presentación no se asoman características de partido político; sobre esta idea, los bumangueses se entusiasman a darle clic al botón "me gusta". Por su lado, la publicación que logra mayores comentarios presenta un mensaje de donación realizada a nombre del movimiento "Lógica, Ética y Estética", con una inversión que beneficia a más de más de cinco mil estudiantes en la ciudad; la publicación está acompañada de un álbum de imágenes, destacando un local con computadoras y niños usuarios. $Y$, finalmente, la publicación que logra un nivel más complejo de 
interacción, al ser la más compartida, centra su mensaje en un "antes" y un "después", ilustrado por unas imágenes de un espacio transformado por una cancha sintética en un sector de la ciudad, con donación del movimiento emergente, pero en esta oportunidad firmada por: Ing, Rodolfo Hernández; este mensaje, multiplicado activamente por los usuarios de Facebook, se convirtió más adelante en uno de los ejes de la campaña de Rodolfo Hernández, siendo la inversión en "canchas sintéticas", uno de las metas incluidas en su Programa de Gobierno.

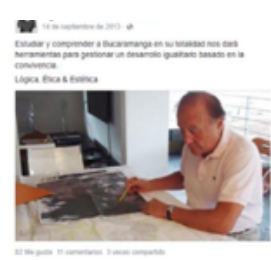

Publicación con mis "mes gusta"

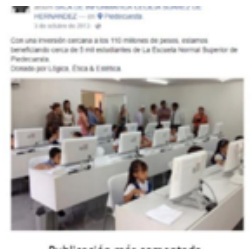

Publicacion mis comentas

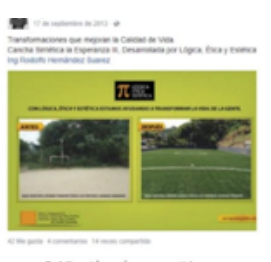

Publikesión miss compertide
Imagen 1: publicaciones con mayor interacción en el año 2013

\section{Año 2014: el discurso anticorrupción}

En este año el discurso anticorrupción fue el eje central discursivo sobre el cual los usuarios de Facebook centraron su atención en los mensajes emitidos por Rodolfo Hernández, generando mayor interacción. En una primera publicación, con más "me gusta" y más compartida, el emisor político despliega argumentos que ilustran una mala gestión en el transporte público (Metrolínea) y señala el vicio en las contrataciones como una de las razones de una condición insuficiente para atender la demanda del servicio. Por su parte, la publicación más comentada es una nota del diario local Vanguardia Liberal, cuyo titular expresa una declaración de Rodolfo Hernández: "El corazón de mi campaña es no robar el fdinero público"; el emisor político acompaña la nota con esta expresión: una opción diferente para los habitantes de Bucaramanga.

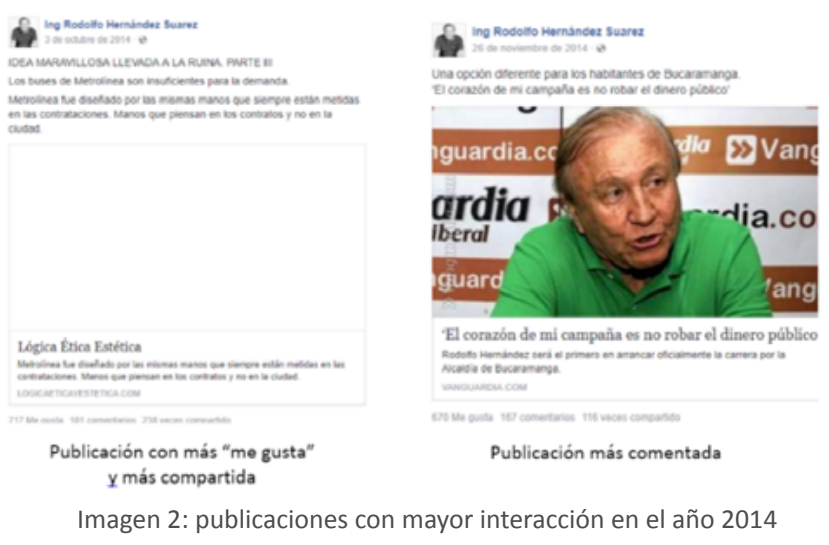

Año 2015: la ganancia colectiva

Este año la publicación con mayor interacción en todos los niveles la despliega el emisor político el mismo día de las elecciones regionales, una vez conocidos los resultados que lo dan como alcalde electo de la ciudad. En el mensaje, se presenta una imagen del político emergente con la expresión ¡Gracias! y un mensaje añadido que enfatiza haber ganado sin compra de votos, se inserta el hashtag que fue usado en el último período de su campaña: \#SinTamalYSinLechona expresión que lo distancia de la conocida manifestación clientelar con la cual algunos políticos tradicionales han buscado en el pasado obtener votos (reuniones públicas que brindan la comida típica de tamal y lechona) y se culmina con la promesa de un verdadero cambio en tono participativo, con el hashtag: \#JuntosPodemosHacerlo.

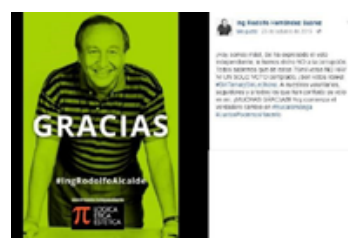

Imagen 3: publicación con mayor interacción en el año 2015 


\section{CONCLUSIONES}

Facebook emerge como una plataforma de potencial revisión para la comunicación política 2.0 , toda vez que deja un registro de interacciones entre emisor político y ciudadanía que, al expresar una interacción propia de la comunicación digital, plantea retos para la interpretación de la opinión pública como construcción social. Esta tendencia de revisión apenas inicia; futuras investigaciones llevarán a rutas diversas en torno a estos retos interpretativos.

Aunque en el primer año del período estudiado, los usuarios mostraron una interacción escasa hacia las publicaciones de Rodolfo Hernández en Facebook, se observa un crecimiento exponencial de las reacciones en los diversos niveles planteados, hacia el final del período, en el cual se concreta un escenario de contienda electoral. El crecimiento exponencial de las reacciones en niveles de mayor complejidad (comentar y compartir) refleja una corresponsabilidad entre un candidato emergente y los ciudadanos, en torno a la circulación del contenido relacionado con la campaña electoral, lo que implica un potencial escenario para la distribución del mensaje en medio de la tendencia de comunicación política 2.0.

Si tomamos como referencia la noción de outsider político como una expresión derivada del malestar democrático, encontramos en nuestra revisión que Rodolfo Hernández va acumulando en el período estudiado una tendencia progresiva en las reacciones a sus publicaciones en Facebook, centradas en temas que parecen derivarse de la llamada fatiga cívica hacia los actores políticos tradicionales.

En general, se refleja en las interacciones analizadas, una atención diferenciada por años hacia núcleos temáticos que caracterizan el discurso de actores políticos emergentes, en fases progresivas: 1.- el reconocimiento de un personaje con características bondadosas, preocupado por el bien común, pero sin afiliación a partido político conocido; 2.- el tema anticorrupción como expresión del descontento hacia partidos tradicionales; y 3.- la euforia de una ganancia colectiva que separa la política tradicional (aquellos) de una ciudadanía que ha terminado apostando a un actor nuevo (nosotros, los ganadores).

\section{REFERENCIAS}

Abad Cisneros, A., \& Trak Vásquez, J. M. (2013). Desafección política en Bolivia, Ecuador y Venezuela en 2010: un análisis comparado. Cuadernos del Cendes, pp. 35-66. Recuperado de http://dialnet.unirioja.es/ servlet/oaiart?codigo $=4651159$

Almond, Gabriel y Sidney Verba (2007). "La cultura política», en Albert Batlle, ed., Diez textos básicos de ciencia política, Barcelona, Editorial Ariel S.A.

Barrios Ferrer, Gonzalo. "Las referencias ideológicas del movimiento bolivariano revolucionario - 200 y la crisis venezolana". Mundo Nuevo. $\mathrm{N}^{\circ} .1 / 2$ Enero-Junio. Caracas 1996. Pp. 27 - 62.

Berlanga, I. y Martínez, E. (2010). Ciberlenguaje y principios de retórica clásica. Redes sociales: el caso Facebook. Enl@ce Rev Venezolana de Información, Tecnología y Conocimiento, 7 (2), 47-61. Recuperado de: file://C:/Users/us/Downloads/Dialnet-CiberlenguajeYPrincipiosDeRetoricaClasica-3294536\%20(4).pdf

Cabañes Martínez, E. (2010). Hacia ciudadanía digital: una carrera de obstáculos. Recuperado de: http://congresos.um.es/filosofiajoven/filosofiajoven2010/paper/ 
viewFile/7301/7021

Canel, M.J. (2006). Comunicación política: una guía para su estudio y práctica. Madrid. Editorial Tecnos.

Dader García, J.L. (2001). La ciberdemocracia posible: reflexión prospectiva a partir de la experiencia en España. Universidad Complutense de Madrid. Madrid, España. Recuperado de: https://revistas.ucm.es/index. php/CIYC/article/viewFile/CIYC0101110177A/7362

Ferré Pavia, C. (2014). El uso de las redes sociales: ciudadanía, política y comunicación. La investigación en España y Brasil. Bellaterra: Institut de la Comunicació, Universitat Autònoma de Barcelona. Recuperado de: http://incom.uab.cat/download/eBook_6_InComUAB_ redessociales.pdf

Fernández Cárdenas, A.Z. (2012). Análisis de la estrategia de campaña del candidato Antanas Mockus (Marzo 2010- Junio 2010) A la luz de las herramientas del marketing político moderno de Philippe Maarek. Bogotá D.C. Universidad Colegio Mayor de Nuestra Señora del Rosario. Recuperado de: file://C:/Users/us/ Downloads/1098669735-2012.pdf

Gómez Zúñiga, R. y otros (2013). Facebook como obra mundana: poetizar la vida y recrear vínculos personales. Editorial Universidad del Valle. Colombia.

González, J.L. (2010). La base electoral de Obama, redes sociales virtuales y reales: los casos de generation engage y moms for Obama. Rev Mediterránea de Comunicación. pp 25-35. Recuperado de: https://rua.ua.es/dspace/bitstream/10045/14323/1/ReMedCom_01_02.pdf

Gutiérrez-Rubí. A. (2015). La transformación digital y móvil de la comunicación política. Barcelona, España. Arial S.A. Recuperado de: file:///C:/Users/us/Downloads/La_transformacion_digital.pdf

Hernández Guzmán, M.I. (2013). Comunicación política en redes sociales. Caso: páginas en Facebook y Twitter de Norman Quijano, Óscar Ortiz y Will Salgado, como candidatos a alcaldes durante la campaña electoral 2012 en el Salvador. Trabajo de tesis para postgrado en Comunicación. Universidad Centroamericana José Simeón Cañas.

Kiss de Alejandro, D. (2006). Niveles de Interacción en la comunicación en internet. En Ámbitos. Num. 15. Pp 45-47. Recuperado de: http://www.redalyc.org/articulo.oa?id=16801503

Martínez Funes, Miriam (2012). Facebook en la comunicación de los partidos políticos españoles con representación parlamentaria: estrategia para periodos no electorales. // Cuadernos de Gestión de Información. P 126-141.

Martínez Martín, M.A. (2012). Redes sociales y políticas 2.0: presencia en Twitter de los candidatos a las elecciones andaluzas de 2012. Trabajo de fin de máster universitario en Comunicación Institucional y Política. Universidad De Sevilla Facultad de Comunicación. Recuperado de: http://fama2.us.es/fco/tmaster/tmaster25.pdf

Murga Frassinetti, Antonio (2008). "Cultura política: un inventario bibliográfico (1985-2005)", Revista de Ciencias Sociales, vol. III, no 121, pp. 107-131.

Norris, Pippa (1999). Critical Citizens: Global Support for Democratic Government, Nueva York, Oxford University Press. 
Pérez Barber, V. (2009). El Político en la red social. Alicante, España. ECU. p. 55

Posada Amaya, J.L. (2011). Mira: internet, participación y democracia. Las nuevas tecnologías y la reconexión con el ciudadano. Rev Civilizar 11 (20): 57-76. Bogotá, Colombia. Recuperado de: http://www.scielo.org.co/ pdf/ccso/v11n20/v11n20a06.pdf

Programa de las Naciones Unidas para el Desarrollo (2004). La democracia en América Latina: hacia una democracia de ciudadanas y ciudadanos. - 2a ed. Buenos Aires: Aguilar, Altea, Taurus, Alfaguara.

Rivas Leone, J.A. (2002). Transformaciones y crisis de los partidos políticos. La nueva configuración del sistema de partidos en Venezuela. Barcelona, España. Institut de Ciencies politiques i socials. Recuperado de: https:// ddd.uab.cat/pub/worpap/2002/hdl_2072_1260/ ICPS202.pdf

Rivas Leone, J. A., \& Araque Calderón, J. (2004). Aventuras y desventuras del populismo latinoamericano. Revista de estudios políticos, (124), 229-244. Recuperado de: http://dialnet.unirioja.es/ servlet/oaiart?codigo $=968202$

Rizo García, M. (2006). George Simmel, Sociabilidad e Interacción. Aportes a la Ciencia de la Comunicación. Cinta Moebio (27). Ciudad de México. pp. 43-60. Recuperado de: http://www.facso.uchile.cl/publicaciones/moebio/27/rizo.pdf

Sánchez Ramos, M.A. (2009). La participación ciudadana en la esfera de lo público. Rev Espacios Públicos 12. (25) 85-102. Toluca, México. Recuperado de: http://www.redalyc.org/pdf/676/67611350006.pdf

\section{Otros sitios consultados:}

Datos de resultados electorales regionales de 2015. Recuperado de: http://www.colombia.com/elecciones/2015/regionales/resultados/alcaldia.aspx?C=AL\&D=27\&M=1

Flimper Blog: 2017. Estadísticas de Redes Sociales: Facebook, Instagram, Linkedln, Twitter, Whatsapp. Recuperado de: https://www.flimper.com/blog/ es/2017-estadisticas-de-redes-sociales-facebook-instagram-linkedin-twitter-whatsapp

\section{Nota de prensa:}

Giraldo, D. (08 de Octubre de 2015). Ganó la opinión en la Alcaldía de Bucaramanga. Vanguardia Liberal. Recuperado de: http://www.vanguardia.com/politica/elecciones-2015/333399-gano-la-opinion-en-la-alcaldiade-bucaramanga

Citar este artículo como: Briceño, Y.; Acevedo, M.; Cogollo, D Sanabria, L. (2017). "Interacción ciudadana frente al mensaje de un actor político emergente en Facebook". En: Revista La Tercera Orilla (19). Bucaramanga:UniversidadAutónoma de Bucaramanga. 
LA TERCERA ORILLA\#19, Diciembre 2017

57 